\title{
Respuesta de anticuerpos IgM contra epítopos inmunogénicos del virus de la hepatitis $A$.
}

\section{Artículo Original}

Aurora Delahanty-Fernández, Irina Valdivia-Alvarez, Janette Trujillo-Brito, Milenen Hernández-Marin, Ivonne Gómez-Cordero, Julio Ventura-Paz, Ariel Palenzuela-Díaz, Carmen Acosta-Bas, Orlando Zulueta-Rodríguez, Antonio M. Rodríguez.

División de Inmunoquímica. Centro de Inmunoensayo. Ciudad de La Habana, Cuba.

\section{RESUMEN.}

Introducción. La hepatitis A es una enfermedad caracterizada por la inflamación aguda del hígado, como consecuencia de la infección por el virus de la hepatitis A (VHA). Debido a las dificultades para la obtención del antígeno natural del VHA empleando el cultivo de tejido, se ha utilizado la tecnología de síntesis de péptidos para la simulación de los principales sitios antigénicos del virus. El objetivo de este trabajo fue determinar la respuesta de anticuerpos IgM contra 3 epítopos inmunogénicos de las regiones estructurales VP1 y VP3 del VHA.

Materiales y Métodos. Los péptidos se sintetizaron en fase sólida, según el método de Merrifield. La pureza se determinó en el sistema High Performance Liquid Chomatography, mediante cromatografía de fase reversa; 38 muestras de suero de pacientes infectados con el VHA y 90 muestras negativas de donantes de sangre fueron evaluadas en un ensayo UMELISA. Como ensayo confirmatorio se empleó el Microelisa Hepanostika HAV IgM (Organon Teknika).

Resultados. Se sintetizaron 2 péptidos de la región VP1(b4 y b6) y un péptido de la región VP3 (b9), y en todos los cromatogramas se obtuvo una señal principal. Para el péptido b4 el $81.82 \%$ de las muestras positivas tuvieron una relación de unidades de fluorescencia/nivel de corte entre 2 y 5 y el $18.18 \%$ por encima de 10; para b6 y b9 fue entre 1 y 5 . Las reactividades encontradas fueron baja, moderada y alta. El péptido más reconocido fue el b4 de la región VP1.

Conclusiones. Estos resultados demuestran que los ensayos empleando péptidos sintéticos pueden ser una buena herramienta en el desarrollo de técnicas tipo ELISA para la detección de infección por el VHA.

(Rev Biomed 2004; 15:11-16)

Palabras clave: Virus de la hepatitis A, péptidos sintéticos, anticuerpos IgM, UMELISA.

Solicitud de sobretiros: Aurora Delahanty-Fernández. Centro de Inmunoensayo, Calle 134 y Ave. 25, Reparto Cubanacán, Apartado 6945, Playa, Ciudad de la Habana, Cuba. Tel.: 208-29 29 Fax: (537) 33-65-14. E-mail: iqhbsag@cie.sld.cu 
A Delahanty-Fernández, I Valdivia-Alvarez, J Trujillo-Brito, M Hernández-Marin, I Gómez-Cordero y col.

\section{SUMMARY.}

Response of IgM antibodies against hepatitis A virus immunogenic epitopes.

Introduction. Hepatitis A is a disease characterized by acute inflammation of the liver, as a consequence of infection by hepatitis A virus (HAV). Due to the difficulties in obtaining the natural antigen of the HAV using cell culture, peptide synthesis technology has been used for the simulation of the main antigenic sites of the virus. The objective of this work was to determine the IgM antibody response against three immunogenic epitopes from the structural regions VP1 and VP3 of HAV.

Materials and Methods. The peptides were synthesized in solid phase, following Merrifield's method. The purity was determined with the High Performance Liquid Chromatography system by means of reverse chromatography. 38 serum samples of HAV positive patients and 90 negative samples of blood donors were evaluated in an UMELISA assay. The MicroElisa HAV IgM (Organon Teknika) was used as a confirmatory assay.

Results. Two peptides of the VP1 region were synthesized ( $b 4$ and b6) and one peptide of the VP3 region (b9), and a main signal was obtained in all the chromatograms. For peptide b4, $81.82 \%$ of samples had a fluorescence/cutoff relation between 2 and 5 , $18.18 \%$ over 10 ; for $\mathrm{b} 6$ and $\mathrm{b} 9$ ratios were between 1 and 5 . Reactivity figures were low, moderate, and high. The most recognizable peptide was b4 from region VP1.

Conclusions. These results show that assays using syntetic peptides can be an apropiate tool in the development of ELISA-type techniques for the detection of infection by HVA.

(Rev Biomed 2004; 15:11-16)

Key words: Hepatitis A virus, synthetic peptides, IgM antibodies, UMELISA.

\section{INTRODUCCIÓN.}

El 80\% de las hepatitis clasificadas en Cuba corresponde a la hepatitis A (1), la que además, constituye la quinta causa de morbilidad por enfermedades transmisibles. Es comúnmente transmitida a través de alimentos y agua contaminados, con un corto período de incubación, entre 3 y 6 semanas. La infección asintomática es común en niños que viven en condiciones higiénico sanitarias pobres en Asia, Africa y Sur América (2).

El agente causal de esta enfermedad es el virus de la hepatitis A (VHA), el que pertenece al género Hepatovirus, dentro de la familia Picornaviridae (3). Es un virus no envuelto con una cadena de ácido ribonucleico (ARN) simple con sentido positivo, cuyo genoma presenta un largo de aproximadamente 7480 nucleótidos. La envoltura está compuesta por las proteínas estructurales VP1, VP2, VP3 y probablemente VP4 (4). La VP1 (30-33 kDa) es codificada por la región genómica 1D, la VP2 (24$25 \mathrm{kDa}$ ) por la región 1B, mientras que la VP3 (21$27 \mathrm{kDa})$ se codifica a partir de $1 \mathrm{C}(5)$.

La definición exacta de la organización antigénica del VHA no está bien reconocida, ya que el sitio antigénico de neutralización depende de la conformación y envuelve residuos de las proteínas VP1 y VP3 $(6,7)$.

Para evaluar la respuesta de anticuerpos de clase IgM contra péptidos sintéticos correspondientes a las glicoproteínas VP1 y VP3 del VHA se sintetizaron 3 péptidos; b4 y b6 de VP1 y b9 de VP3.

\section{MATERIAL Y MÉTODOS.} Síntesis química de los péptidos:

Los péptidos se sintetizaron en fase sólida, por el método descrito por Merrifield en 1963, siguiendo la estrategia Boc en bolsas de polipropileno (Biotech. Instruments, EUA) (8). Las reacciones de acoplamiento se realizaron por activación del grupo carboxilo de cada aminoácido con cantidades equivalentes de DIPCDI $0,2 \mathrm{~mol} / \mathrm{L}$ en diclorometano (DCM). La eficiencia del acoplamiento de los aminoácidos protegidos se verificó con ayuda del ensayo de ninhidrina. La eliminación de la protección temporal (Boc-), incluyendo la del $\mathrm{NH}_{2}$-terminal, se realizó por un tratamiento con ácido trifluoracético al $37,5 \%$ en DCM (9). El procedimiento empleado para la desprotección final fue el conocido como el "Low-

\section{Revista Biomédica}




\section{Anticuerpos IgM contra péptidos sintéticos del virus de la hepatitis A.}

High”, con ácido fluorhídrico (Fluka, Suiza). Posteriormente las bolsas se lavaron con éter dietílico y se secaron al vacío. Al producto final crudo se le realizó la extracción del péptido con ácido acético al $30 \%$ en $\mathrm{H}_{2} \mathrm{O}$ destilada. El extracto final se diluyó con agua y se liofilizó, en un equipo Edwards de tecnología inglesa. A cada uno de los péptidos se le añadió en el extremo carboxilo terminal dos lisinas, para facilitar la unión a la placa de ultramicroELISA.

\section{Purificación de los péptidos sintéticos:}

La determinación de la pureza de los péptidos sintéticos se realizó en el sistema HPLC (High Performance Liquid Chomatography) mediante cromatografía de fase reversa (RP-HPLC) (10) .En una columna Biotech RP18 (Pharmacia) se aplicaron $200 \mu \mathrm{L}$ de las muestras ( $0,2 \mathrm{mg}$ de péptido). La disolución A fue TFA $0,1 \%$, acetonitrilo $2 \%$ en $\mathrm{H}_{2} \mathrm{O}$ y la disolución B TFA $0,05 \%$ en acetonitrilo. El gradiente fue entre $0-60 \% \mathrm{~B}$ (33 min); la velocidad de flujo de $0,5 \mathrm{~mL} / \mathrm{min}$; la velocidad del papel de 2 $\mathrm{mm} / \mathrm{min}$; la sensibilidad de $0,1 \mathrm{y}$ la temperatura de $22^{\circ} \mathrm{C}$.

\section{Muestras:}

Para evaluar la respuesta de anticuerpos de clase IgM contra los péptidos sintetizados se evaluaron 38 muestras de suero de pacientes infectados con el VHA, obtenidas de los Centros de Higiene y Epidemiología de Ciudad de la Habana y Pinar del Río, Cuba. Estas muestras fueron probadas previamente por el MicroELISA Hepanostika HAV IgM, de la firma Organon Teknika. Para establecer el nivel de corte se evaluaron 90 muestras negativas de donantes de sangre del Banco de Sangre Provincial de Ciudad de la Habana, Cuba.

\section{Recubrimiento de la fase sólida:}

Las placas ultramicroELISA (Greiner Labortechnik, Alemania) fueron recubiertas con 16 $\mu \mathrm{L} /$ pocillo durante 4 horas a $45^{\circ} \mathrm{C}$ con cada uno de los péptidos a $4 \mu \mathrm{g} / \mathrm{mL}$ en una disolución reguladora carbonato-bicarbonato, $0,05 \mathrm{~mol} / \mathrm{L} ; \mathrm{pH}$ 9.6. La fase sólida se lavó con PBS-Tween (8 g de NaCl; $1.215 \mathrm{~g}$ de $\mathrm{Na}_{2} \mathrm{HPO}_{4} 2 \mathrm{H}_{2} \mathrm{O} ; 0.2 \mathrm{~g}$ de $\mathrm{KH}_{2} \mathrm{PO}_{4} ; 0.2 \mathrm{~g}$ de $\mathrm{NaN}_{3} ; 0.5 \mathrm{~mL}$ de Tween-20; en $1000 \mathrm{~mL}$ de agua destilada, $\mathrm{pH}$ 7.3) y posteriormente se bloqueó con una disolución de preservo (sacarosa al $5 \%$ y BSA al $1 \%$ en PBS-Tween), durante 18 horas a temperatura ambiente $\left(20-25^{\circ} \mathrm{C}\right)$. La disolución de preservo se aspiró y la fase sólida se dejó secar a $37^{\circ} \mathrm{C}$ durante 2 horas. Las placas recubiertas se conservaron a $4^{\circ} \mathrm{C}$, con una cubierta protectora, hasta el momento de su uso.

\section{Ensayo UMELISA:}

Las muestras a evaluar se diluyeron 1:40 en disolución amortiguadora suero de carnero al $5 \%$ en Tris- $\mathrm{HCl}(15 \mathrm{mmol} / \mathrm{L}$ de Tris; $\mathrm{pH} 7.8$ y $0.05 \%$ Tween-20) y se incubaron 1 hora a $37^{\circ} \mathrm{C}$ en las placas de reacción. Después de lavar tres veces con la disolución amortiguadora Tris- $\mathrm{HCl}$, se adicionó un conjugado anti-IgM humana en carnero, marcado con fosfatasa alcalina (Böehringer Mannheim $\mathrm{GmbH}$, Alemania), y se incubó 1 hora a $37^{\circ} \mathrm{C}$.

En las mismas condiciones se realizó un nuevo lavado y se añadió el sustrato fluorigénico 4metilumbeliferilfosfato (Koch Light Ltd. Haverhill, Suffolk, England), que se incubó durante 30 minutos a temperatura ambiente.

En todos los ensayos se evaluaron los controles positivos y negativos del ensayo. Las muestras se analizaron por duplicado.

\section{Parámetros de calidad del ensayo. Nivel de corte:}

El nivel de corte se determinó como la media de la fluorescencia de las muestras negativas +3 desviaciones estándares.

\section{Clasificación de las muestras. Muestras positivas:}

Las muestras consideradas como positivas fueron aquellas donde la relación unidades de fluorescencia (UF)/ Nivel de corte (Nc) fue ${ }^{3} 1$.

Muestras de alta, moderada y baja reactividad: Las muestras de alta reactividad son las que Vol.15/No. 1/Enero-Marzo, 2004 
A Delahanty-Fernández, I Valdivia-Alvarez, J Trujillo-Brito, M Hernández-Marin, I Gómez-Cordero y col.

\section{Cuadro 1}

Secuencia de aminoácidos de los péptidos del VHA sintetizados.

\begin{tabular}{cccc}
\hline PÉPTIDO & REGIÓN & POSICIÓN & PESO MOLECULAR \\
\hline B4 & VP1 & $10-35$ & 2815.62 \\
B6 & VP1 & $170-196$ & 3217.06 \\
B9 & VP3 & $34-58$ & 3241.16 \\
\hline
\end{tabular}

tienen fluorescencia por encima de $30 \mathrm{UF}$; las de moderada entre 15 y 30 UF y las de baja reactividad por debajo de $15 \mathrm{UF}$.

\section{Análisis estadístico:}

A la población de muestras de donantes de sangre y las muestras positivas se les realizó la distribución de frecuencias. Para realizarla se calcularon las frecuencias absoluta, absoluta acumulada y relativa acumulada utilizando la prueba estadística Frecuencia del programa Microsoft Excel 2000 .
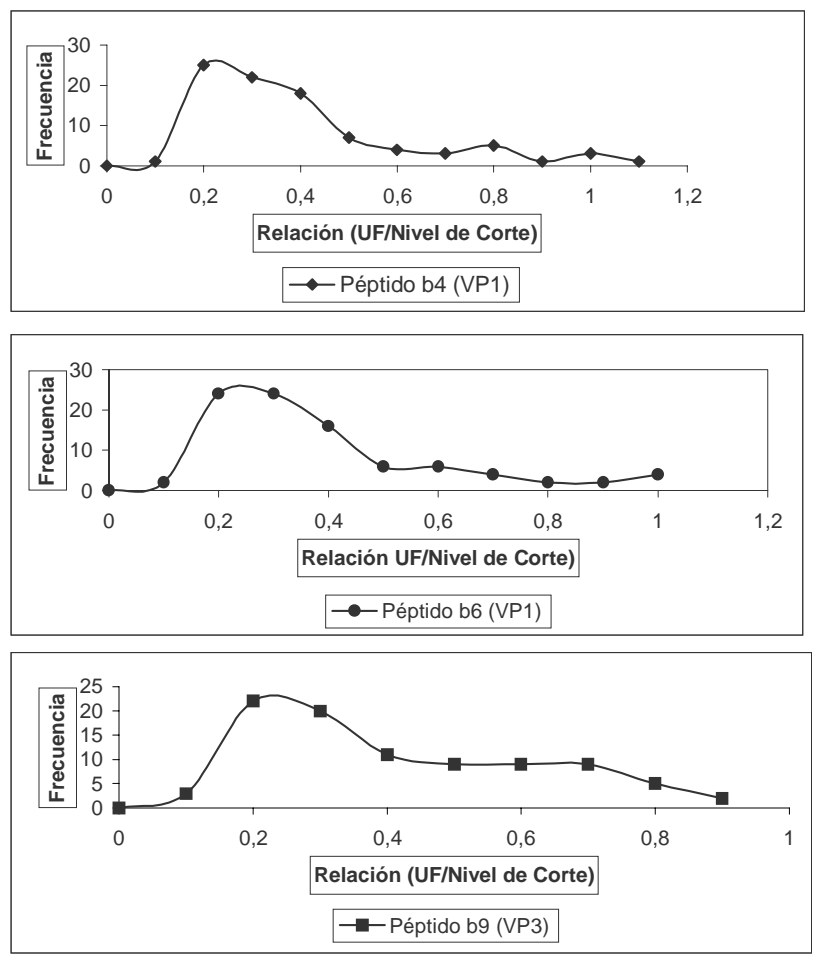

Figura 1.- Distribución de las muestras negativas para cada uno de los péptidos.

\section{Revista Biomédica}

\section{Equipos:}

Para la lectura de la fluorescencia emitida se utilizó el lector PR-521 de la Tecnología SUMA, acoplado a una computadora y para el lavado de las placas se empleó el Lavador MAS 301-M, ambos equipos del Centro de Inmunoensayo, Ciudad de la Habana, Cuba.

\section{RESULTADOS.}

Con el método de Merrifield se sintetizaron tres péptidos correspondientes a zonas antigénicas de la envoltura VP1 (b4, 10-35; b6 170-196) y VP3 (b9, 34-58) (11,12) (cuadro 1). Los tres péptidos sintetizados fueron purificados a través del sistema RPHPLC obteniéndose en todos los cromatogramas una señal principal.

En la figura 1 se muestran los resultados de las muestras negativas para cada uno de los péptidos, las que siguen una distribución normal.

La respuesta de anticuerpos IgM para cada uno de los péptidos por separado fue determinada por el UMELISA, analizando 38 muestras positivas. Para el péptido b4 (VP1), 33 muestras fueron

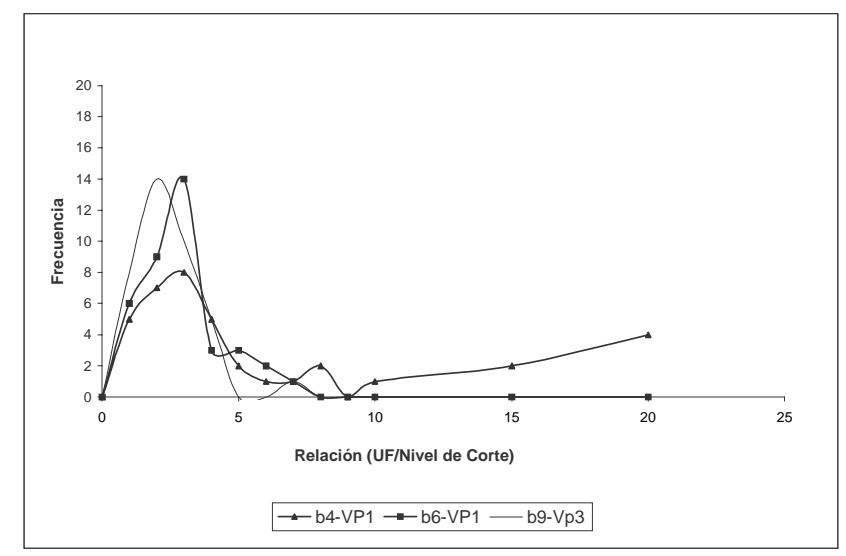

Figura 2.- Distribución de las muestras positivas para uno de los péptidos. 
Anticuerpos IgM contra péptidos sintéticos del virus de la hepatitis A.

Cuadro 2

Reactividad de las muestras de pacientes infectados por el VHA para cada uno de los péptidos.

\begin{tabular}{lccc}
\hline & $\begin{array}{c}\text { Péptido b4 } \\
\text { (VP1) }\end{array}$ & $\begin{array}{c}\text { Péptido b6 } \\
\text { (VP1) }\end{array}$ & $\begin{array}{c}\text { Péptido b9 } \\
\text { (VP3) }\end{array}$ \\
\hline Total de muestras & 38 & 38 & 38 \\
Positivas en UMELISA & 33 & 29 & 30 \\
Alta Reactividad $(*)$ & 24 & 12 & 19 \\
Moderada Reactividad $(\dagger)$ & 9 & 16 & 11 \\
Baja Reactividad $(\ddagger)$ & 0 & 1 & 0 \\
\hline
\end{tabular}

* Señal de fluorescencia de 30 UF

$\ddagger$ Señal de fluorescencia menor de 15 UF

positivas, de ellas el $81.82 \%$ tuvieron una relación UF/Nc entre 2 y 5 y el $18.18 \%$ por encima de 10 . Para los péptidos b6 y b9, aunque con un reconocimiento algo similar en cuanto a cantidad de muestras positivas, las relaciones de las muestras estuvieron entre 1 y 5 (figura 2).

En el cuadro 2 se muestra la reactividad de los sueros positivos para cada uno de los péptidos sintetizados. Las reactividades encontradas fueron baja, moderada y alta.

\section{DISCUSIÓN.}

Los sitios antigénicos del VHA están bien conservados entre aislamientos humanos del virus y los anticuerpos neutralizantes estrechamente relacionados (13). La complejidad intrínseca de la estructura del sitio inmunodominante del VHA constituye un obstáculo para el desarrollo de proteínas recombinantes inmunoreactivas, por eso se ha estudiado la posibilidad de sintetizar péptidos sintéticos capaces de imitar sitios antigénicos de las regiones VP1 y VP3 (14).

El péptido sintético b4, con secuencia 10-35 de la región VP1, que fue el más reconocido por las muestras positivas al VHA presentó una elevada respuesta antipéptido en líquido ascítico de ratones, inmunizado con antígeno natural (15). Varios autores han establecido el papel primordial que presenta la proteína de la envoltura VP1 en la antigenicidad y $\dagger$ Señal de fluorescencia entre 15 y 30 UF

además, han demostrado que al igual que la VP1, la VP3, también se encuentra involucrada en el reconocimiento (16,17). Esto explica el reconocimiento de estos péptidos por los anticuerpos IgM con los sueros de pacientes infectados con el VHA frente a los péptidos sintéticos (b4,b6,b9) de las regiones VP1 y VP3 del virus.

Los anticuerpos de clase IgM contra el VHA aparecen precozmente en la enfermedad, y coinciden con el inicio de los síntomas, sus títulos son altos durante dos o tres meses y, en casos poco frecuentes se pueden detectar hasta seis meses después de ocurrida la infección $(18,19)$.

\section{REFERENCIAS.}

1.Delgado G. Actualización de las hepatitis virales en Cuba. Presentado en: IV Taller sobre Hepatitis Virales, Centro de Ingeniería Genética y Biotecnología, Mayo 2000, Ciudad de la Habana, Cuba.

2. Yang Y, Vyas GN. Immunodiagnosis of viral hepatitis A to E and Non-A to -E. Clin Diagn Lab Immunol 1996; 3:247-56.

3. Murphy FA, Faiquet CM, Bishop DHL, Ghabrial SA, Jarvis AW, Martelli GP, et al. Virus taxonomy. Classification and nomenclature of viruses. Sixth report of the International Committee of Taxonomy of Viruses. Arch Virol 1995; (suppl):10.

4. Lemon SM, Robertson BH. Current Perspectives in the virology and molecular biology of hepatitis A virus. Sem Virol 1993; 4:285-295. 


\section{A Delahanty-Fernández, I Valdivia-Alvarez, J Trujillo-Brito, M Hernández-Marin, I Gómez-Cordero y col.}

5. Wheeler C, Robertson B, Van Nest G, Dina D, Bradley D, Fields H. Structure of the hepatitis A virion: peptide mapping of the capside region. J Virol 1986; 58:307-13.

6. Ping L, Lemon SM. Antigenic structure of human hepatitis A virus defined by analysis of escape mutants selected against murine monoclonal antibodies. J Virol 1992; 66:220822.

7. Stapleton J, Lemon SM. Neutralization escape mutants define a dominant inmunogenic neutralization site on hepatitis A virions. J Virol 1987; 61:491-93.

8. Merrifield RB. Peptide synthesis. I. The synthesis of a tetrapeptide. J Am Chem Soc 1963; 85:2149-54.

9. Houghten RA. Simultaneous multiple peptide synthesis: The rapid preparation of large numbers of discrete peptides for biological, immunological and methodological studies. Biotechniques 1986; 4:522-7.

10. Stone KL, LoPresti MB, Myron J, DeAngelis R, Williams KR. Enzymatic digestion of proteins and HPLC peptide isolation. In: Academic press, editors. A practical guide to protein and peptide purification for microsequencing, Academic Press, Inc 1989:31-47.

11. Cohen JI, Ticehurst JR, Purcell RH, Buckler-White A, Baroudy B. Complete nucleotide sequence of wild-type hepatitis A virus: Comparison with different strains of hepatitis A virus and other picornaviruses. J Virol 1987; 611:50-4.

12. Bosch A, González-Dankaart JF, Haro I, Gajardo R, Pérez JA, et al. A new continuous epitope of hepatitis A virus. J Med Virol 1998; 54:95-102.

13. Lemon SM, Ping LH, Day S, Cox E, Jansen R, AmphlettE, et al. Immunobiology of hepatitis A virus. En: Hollinger FB, Lemon SL and Margolis $\mathrm{H}$ ed. Molecular aspect of picornavirus infection and detection. Washington: American Society for Microbiology; 1991. p. 20-4.

14. Mattioli S, Imberti L, Stellini R, Primi D. Mimicry of the immunodominant conformation-dependent antigenic site of hepatitis A virus by motifs selected from synthetic peptide libraries. J Virol 1995; 69:5294-99.

15. Acosta C, Baluja I, Amores I, Brito A, Delahanty A, Miguez J, et al. Antigenicidad e inmunogenicidad de péptidos sintéticos de tres proteínas de la cápside del virus de la hepatitis A. Revista CENIC, Ciencias Biológicas 2000; 31(2):105-6.

\section{Revista Biomédica}

16. Haro I, Pinto RM, González, Dankaaart JF, Pérez J, Reig F, et al. Anti-hepatitis A virus antibody response elicited in mice by different forms of a synthetic VP1 peptide. Microbiol Immunol 1995; 39:484-8.

17. Ping LH, Jansen RW, Staplenton JT, Cohen JI, Lemon SM. Identification of an immunodominant antigent site involving the capside protein VP3 of hepatitis A virus. Proc Natl Acad Sci USA 1988; 85:8281-5.

18. Lemon SM, Brown CD, Brooks DS, Simms TE, Bracroft WH. Specific immunoglobulin M response to hepatitis A virus determined by solid phase radioimmunoassay. Infect Immunol 1980; 28:927-36.

19. Duermeyer W. Application of ELISA for the diagnosis and epidemiology of hepatitis A. Tesis; Universidad de Utrecht; Facultad de Medicina, Rodopy, Amsterdam;1980; 45:151. 